\title{
Effect of stimulation of the subthalamic nucleus on oral control of patients with parkinsonism
}

\author{
Michèle Gentil, Pedro Garcia-Ruiz, Pierre Pollak, Alim-Louis Benabid
}

\begin{abstract}
Objectives-To assess the oral system of parkinsonian patients treated with chronic stimulation of the bilateral subthalamic nucleus (STN) to evaluate precisely the effectiveness of this procedure on the articulatory organs.

Methods-Load sensitive cantilevers were used to sample ramp and hold force contractions generated by the upper lip, lower lip, and tongue. The subject was given the instruction to produce forces as rapidly and as accurately as possible in response to the target signal (ranging from 0.25 to $2 \mathrm{~N}$ ), which appeared on a screen. Maximal force of each effector organ was also measured. Fourteen healthy control subjects and 10 patients participated in this study. After an overnight fast the patients were evaluated in the morning under two conditions: during bilateral stimulation and 1 hour after stopping STN stimulation.

Results-During STN stimulation, dynamic and static control of the articulatory organs were improved: the maximal strength of the articulatory organs, their accuracy to reach the target, and the precision of the hold phase increased. In addition, the reaction time and the rise time of the ramp phase decreased. Patients' speech as assessed by the item 18 of the unified Parkinson's disease rating scale (UPDRS) was greatly improved by electrical stimulation of the STN

Conclusions-Improvement of oral control of the stimulated patients suggests that STN stimulation modulates neuronal structures involved in speech. However, more patients have to be evaluated for a fuller understanding of the effect of this surgical procedure on speech.

(F Neurol Neurosurg Psychiatry 1999;67:329-333)
\end{abstract}

Keywords: parkinsonism; surgical therapy; subthalamic nucleus; oral control (speech)

Neurology, Fundacion

Jimenez-Diaz, Madrid,

Spain

P Garcia-Ruiz

Correspondence to:

Dr Michèle Gentil, Centre

Hospitalier de Grenoble,

Clinique Neurologique, BP

217, 738043, France.

Telephone 00334767658

52; email

michele.Gentil@ujf-grenoble.fr

Received 11 December 1998 and in revised form

26 March 1999

Accepted 7 April 1999 effective for the main signs of parkinsonismbradykinesia, rigidity, and tremor-and greatly improves parkinsonian motor disability. ${ }^{5}$ The importance of STN input in the control of non-primary motor areas which have a dominant role in the control of movements in parkinsonian patients has been demonstrated. ${ }^{6}$ Although the effect of STN stimulation on limb control is known, the precise effect of STN stimulation on oral control is not. Quantitative data relative to speech in patients treated with STN stimulation have not been obtained. It is important to evaluate speech in patients treated with STN stimulation because we know that other surgical procedures have detrimental effects on speech; the risk of speech dysfunctions was particularly high with bilateral thalamotomy, surgical intervention used earlier to treat tremor. ${ }^{7-10}$ Dysarthria was also seen in patients with electrical stimulation of the ventral intermediate nucleus (VIM) of the thalamus, a valuable therapeutic procedure against the tremor of Parkinson's disease. ${ }^{11}{ }^{12}$

Force has been considered as one of the likely variables controlled by the nervous system in producing motor behaviour. ${ }^{13}$ The usefulness of force transducers for evaluating impairments in the control of lip, jaw, and tongue muscles in patients with motor speech disorders has been shown in several investigations. ${ }^{14-19}$ The evaluation of nonspeech oral strength has been recognised as a worthwhile tool to assess the effects of therapies on speech. ${ }^{20}$ To estimate the effectiveness of bilateral STN stimulation on the oral system in parkinsonian patients, we investigated force measurements of the articulatory organs, especially the lips and tongue, and we evaluated speech with item 18 of the UPDRS, under two conditions: during stimulation and 1 hour after stopping stimulation.

\section{Methods}

SUBJECTS

We studied 10 patients with Parkinson's disease (six men and four women) who underwent bilateral stereotaxic electrode implantation into the STN for chronic high frequency stimulation. At the time of surgery their mean (SD) age was 49 (9) years and the mean duration of symptoms was 11 (40) years. Evaluations of the oral system were performed within a period from 3 months to 3 years after surgery. The selection criteria were the speech impairment of the patients perceptually evaluated-without medication and without stimulation-as moderate or marked, as well as the patients' consent. Dysphagia was not present in these patients. In addition, 14 


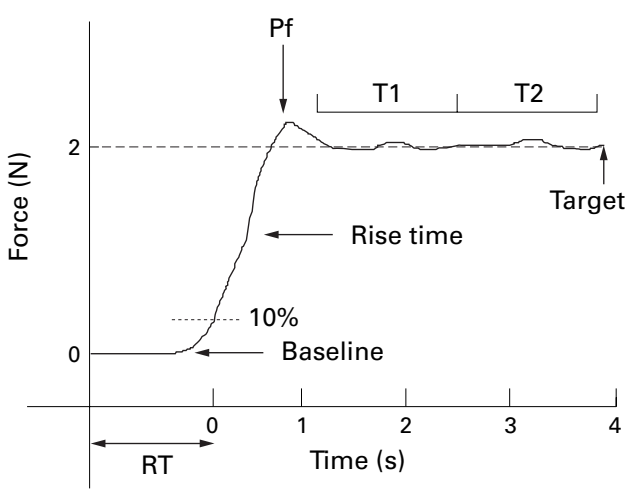

Figure 1 Schematic diagram of the parametric measures: $R T=$ reaction time, $P f=$ peak force, rise time $=$ time during the ramp phase (10\% to $90 \%$ of peak force), T1 and

T2=mean force during the last 3 seconds of the hold phase.

healthy subjects with a mean age of 56 (SD 7) years served as control subjects. This study was approved by the Grenoble University Hospital ethics committee.

FORCE TASK TESTING AND MOTOR EXAMINATION Load sensitive devices (Neuro Logic Inc, Bloomington, IN, USA) were used to sample compression forces generated by the upper and lower lips and tongue. The device slid along a jaw yoke that was encapsulated in a mouldable dental impression block and placed between the molars. On the screen of the oscilloscope put in front of the subject- who was seated on a dental chair in a Faraday cage - the target and the actual force transducer waveforms were displayed on line. The target levels were 0.25 , $0.5,1$, and $2 \mathrm{~N}$, corresponding to forces within speech range The subject was given the instruction to generate forces from baseline as rapidly and as accurately as possible in response to the target signal which appeared on the screen. The rapid phase of force increase to reach the target was followed by a stabilisation to the target level for 3 seconds. We recorded for each articulatory organ 10 consecutive contractions at each of the four target levels, which were randomised, and two maximal forces. The patients were evaluated in the morning after a period of at least 10 hours without medication under two conditions: during bilateral STN stimulation, and 1 hour after stopping STN stimulation.

Before each force examination, the motor disability of the patients was assessed by means of the UPDRS, part 3, items 18-31, using a 0

Table 1 Motor examination of patients

\begin{tabular}{llllll}
\hline & UPDRS & \multicolumn{3}{l}{ \% Improvement } & \multicolumn{2}{l}{ Speech (item 18) } \\
\cline { 2 - 6 } & $\begin{array}{l}\text { Without } \\
\text { Ptimulation }\end{array}$ & $\begin{array}{l}\text { With } \\
\text { stimulation }\end{array}$ & With stimulation & $\begin{array}{l}\text { Without } \\
\text { stimulation }\end{array}$ & $\begin{array}{l}\text { With } \\
\text { stimulation }\end{array}$ \\
\hline 1 & 25 & 11 & 56 & 2 & 1 \\
2 & 62 & 19 & 69 & 2 & 0 \\
3 & 64 & 29 & 55 & 2 & 1 \\
4 & 25 & 9 & 64 & 2 & 1 \\
5 & 56 & 16 & 71 & 2 & 2 \\
6 & 62 & 36 & 42 & 3 & 1 \\
7 & 48 & 14 & 70 & 2 & 2 \\
8 & 27 & 5 & 82 & 3 & 1 \\
9 & 36 & 6 & 83 & 2 & 1 \\
10 & 45 & 6 & 87 & 2 &
\end{tabular}

UPDRS= Unified Parkinson's disease rating scale, part 3, item 18-31.

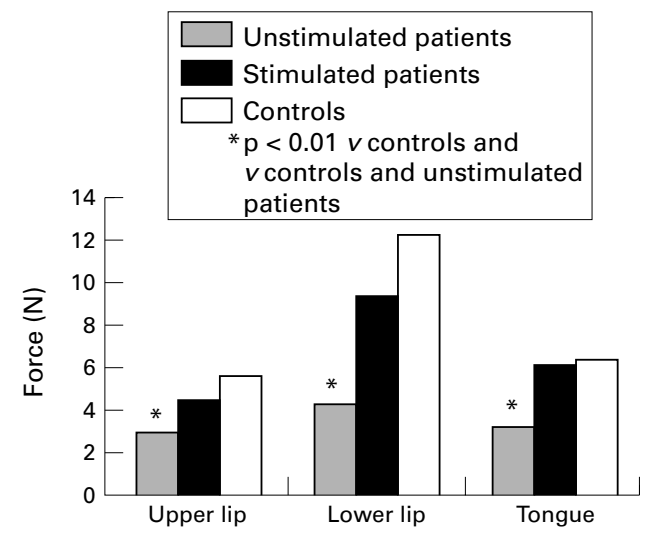

Figure 2 Maximal voluntary forces $(N)$ of the upper lip, lower lip, and tongue for the controls and stimulated, and unstimulated patients.

(no impairment) to 4 (severe impairment) scale, maximum score $=108 .^{21}$ In particular, speech was evaluated with item 18 of the UPDRS: $0=$ normal; $1=$ slight loss of expression, diction, and/or volume; $2=$ monotone, slurred but understandable, moderately impaired; $3=$ marked impairment, difficult to understand; $4=$ unintelligible.

MEASURES AND DATA ANALYSIS

Maximal voluntary forces of the lips and tongue were measured, as well as the following four variables of the ramp and hold force task (fig 1): (1) reaction time, defined as the time interval from the time the target signal appeared on the screen until the force had reached $10 \%$ of peak force; (2) peak force during the force ramp - that is, the highest force level occuring in the 1 second period immediately after $0.1 \mathrm{~N}$; (3) rise time - that is, the time during the ramp phase ( $10 \%$ to $90 \%$ of peak); (4) mean and SD of force output during the last 3 seconds of the hold phase. The first three variables estimated dynamic fine force control, and the last one, static force control. These variables were quantified from the digitised records of each articulatory organ for each subject.

The data were submitted to sequential one way analyses of variance (ANOVAs) and Tukey tests $(p<0.01)$ to characterise the significant difference between the three groups of subjects: controls and unstimulated and stimulated patients. Two sample $t$ tests were also used to estimate significant differences between two groups of subjects. To estimate the precision of certain variables in relation to the target, such as mean amplitude of peak force or mean amplitude during the hold phase, we calculated for each trial the difference between the amplitude of the actual variable and that of the target force, then we evaluated the mean difference for comparison between the patients.

\section{Results}

The motor disability and speech assessment of the patients with and without stimulation are presented in table 1 . The UPDRS mean motor score greatly decreased in the stimulated patients, who improved their motor performance by $42 \%$ to $87 \%$. All the items of the 


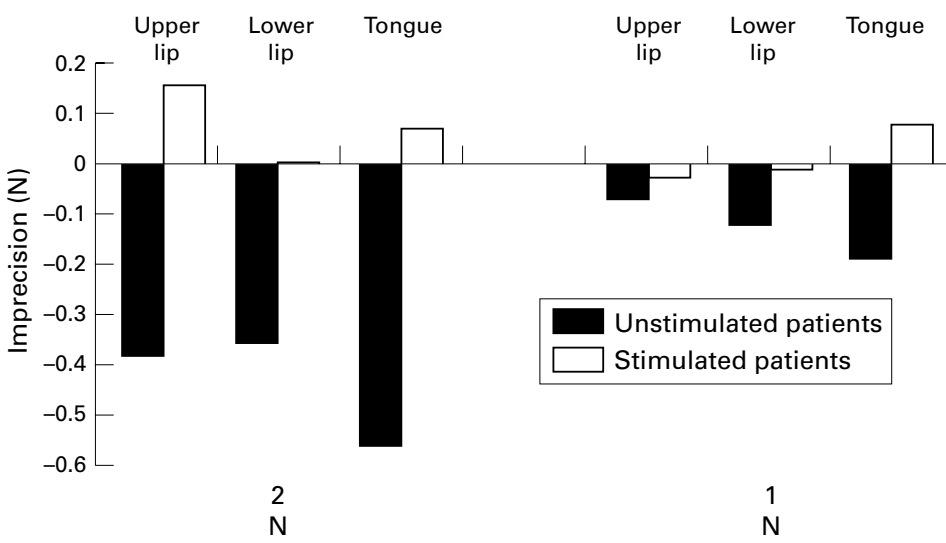

Figure 3 Imprecision of peak force of the upper lip, lower lip and tongue at the $2 \mathrm{~N}$ and $1 N$ target level in the stimulated and unstimulated patients.

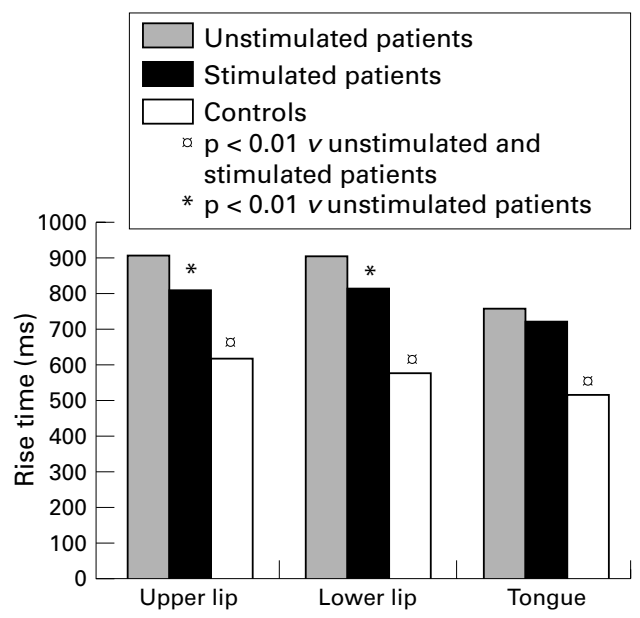

Figure 4 Force rise time (ms) of the upper lip, lower lip, and tongue for the controls and stimulated and unstimulated patients.

UPDRS were improved, mostly rigidity, hand movements, leg agibility, and gait. Speech impairment assessed by the UPDRS (item 18) was significantly improved. In the unstimulated patients, eight were assessed as moderately impaired, with a monotonic voice but understandable, and two were difficult to understand with marked impairment. With stimulation we noted that one patient had a normal speech, seven patients had a small loss of diction or volume, and two patients had a slurred speech but understandable. The median score before STN stimulation was 2 and after STN stimulation it was 1 .

Figure 2 shows maximal voluntary forces (MVFs) of the three articulatory organs for the unstimulated and stimulated patients, and for the control subjects. A one way ANOVA disclosed that the MVF of these last were significantly greater $(\mathrm{p}<0.01, F=12.25$ for the upper lip, 19.61 for the lower lip, and 4.48 for the tongue) than those of the unstimulated patients, but not significantly greater than those of the stimulated patients. The unstimulated patients yielded significantly smaller maximal forces than the stimulated patients: MVF increased by $51 \%$ (upper lip), $117 \%$ (lower lip), and $88 \%$ (tongue) when the patients were stimulated.

For any articulatory organ, mean reaction time of the stimulated patients was shorter than that of the unstimulated patients but this difference was only significant for the tongue $(t=2.79, \mathrm{p}<0.01)$. In addition, the patients exhibited a larger variability than the controls as indicated by the large SD.

Figure 3 shows the precision of peak force of the upper lip, lower lip, and tongue at the $2 \mathrm{~N}$ and $1 \mathrm{~N}$ target level in the unstimulated and stimulated patients. The unstimulated patients undershot the target, whatever the articulatory organ and the target level. They were less precise than the stimulated patients. The difference in precision was significant $(p<0.01)$ between both groups of patients (for the upper lip, $t=3.17$ at $1 \mathrm{~N}, t=3.59$ at $2 \mathrm{~N}$; for the lower lip, $t=3.08$ at $1 \mathrm{~N}, t=5.06$ at $2 \mathrm{~N}$; for the tongue, $t=7.05$ at $1 \mathrm{~N}, t=7.67$ at $2 \mathrm{~N}$ ). The peak force of the lower lip was closer to the target than that of the other effector organs in the stimulated patients; this accuracy was particularly noted at the $2 \mathrm{~N}$ target level.

Figure 4 presents the average force rise time and SD for each articulatory organ in the control subjects and unstimulated and stimulated patients. Force rise time of the controls was significantly shorter $(p<0.01)$ than that of the unstimulated and stimulated patients whatever the articulatory organ. Force rise time of the stimulated patients was significantly shorter than that of the unstimulated patients for the upper lip $(t=2.95, \mathrm{p}<0.01)$ and the lower lip $(t=2.67, \mathrm{p}<0.01)$.

Two sample $t$ tests showed that no significant difference was seen between the two periods of the hold phase. Results are reported for the first period. Table 2 shows the mean amplitude of the force of the upper lip, lower lip, and tongue during the first period of the hold phase in the control subjects and stimulated and unstimulated patients, at each target level. The control subjects were very close to the target, and this precision was steady as indicated by the relatively low SD. The stimulated patients were significantly closer to the target and consequently more precise than the unstimulated patients for the three articulatory organs, as

Table 2 Mean amplitude of the force (SD) (N) during the first period of the hold phase

\begin{tabular}{|c|c|c|c|c|c|c|c|c|c|c|c|c|}
\hline & \multicolumn{3}{|l|}{$0.25 N$} & \multicolumn{3}{|l|}{$0.50 \mathrm{~N}$} & \multicolumn{3}{|l|}{$1 N$} & \multicolumn{3}{|l|}{$2 N$} \\
\hline & $U L$ & $L L$ & $T$ & $U L$ & $L L$ & $T$ & $U L$ & $L L$ & $T$ & $U L$ & $L L$ & $T$ \\
\hline Control subjects & $\begin{array}{l}0.24 \\
(0.04)\end{array}$ & $\begin{array}{l}0.25 \\
(0.04)\end{array}$ & $\begin{array}{l}0.26 \\
(0.04)\end{array}$ & $\begin{array}{l}0.47 \\
(0.05)\end{array}$ & $\begin{array}{l}0.50 \\
(0.04)\end{array}$ & $\begin{array}{l}0.49 \\
(0.06)\end{array}$ & $\begin{array}{l}0.97 \\
(0.08)\end{array}$ & $\begin{array}{l}0.99 \\
(0.07)\end{array}$ & $\begin{array}{l}0.98 \\
(0.09)\end{array}$ & $\begin{array}{l}1.95 \\
(0.11)\end{array}$ & $\begin{array}{l}1.95 \\
(0.13)\end{array}$ & $\begin{array}{l}1.92 \\
(0.14)\end{array}$ \\
\hline Stimulated patients & $\begin{array}{l}0.21 \\
(0.06)\end{array}$ & $\begin{array}{l}0.22 \\
(0.09)\end{array}$ & $\begin{array}{l}0.23 \\
(0.06)\end{array}$ & $\begin{array}{l}0.37 \\
(0.07)\end{array}$ & $\begin{array}{l}0.45 \\
(0.07)\end{array}$ & $\begin{array}{l}0.46 \\
(0.13)\end{array}$ & $\begin{array}{l}0.87 \\
(0.10)\end{array}$ & $\begin{array}{l}0.87 \\
(0.10)\end{array}$ & $\begin{array}{l}0.91 \\
(0.13)\end{array}$ & $\begin{array}{l}1.70 \\
(0.03)\end{array}$ & $\begin{array}{l}1.74 \\
(0.13)\end{array}$ & $\begin{array}{l}1.83 \\
(0.22)\end{array}$ \\
\hline Unstimulated patients & $\begin{array}{l}0.20 \\
(0.05)\end{array}$ & $\begin{array}{l}0.24 \\
(0.11)\end{array}$ & $\begin{array}{l}0.21 \\
(0.10)\end{array}$ & $\begin{array}{l}0.41 \\
(0.08)\end{array}$ & $\begin{array}{l}0.42 \\
(0.13)\end{array}$ & $\begin{array}{l}0.38 \\
(0.16)\end{array}$ & $\begin{array}{l}0.80 \\
(0.16)\end{array}$ & $\begin{array}{l}0.76 \\
(0.26)\end{array}$ & $\begin{array}{l}0.67 \\
(0.28)\end{array}$ & $\begin{array}{l}1.54 \\
(0.04)\end{array}$ & $\begin{array}{l}1.45 \\
(0.48)\end{array}$ & $\begin{array}{l}1.25 \\
(0.63)\end{array}$ \\
\hline
\end{tabular}

$\mathrm{UL}=\mathrm{Upper}$ lip; $\mathrm{LL}=$ lower lip; $\mathrm{T}=$ tongue. Values in parentheses are SD. 
shown by two sample $t$ tests - that is, for the upper lip at $0.5 \mathrm{~N}(t=2.68, \mathrm{p}<0.01), 1 \mathrm{~N}$ $(t=3.37, \mathrm{p}<0.01)$, and $2 \mathrm{~N}(t=3.32, \mathrm{p}<0.01)$; for the lower lip at $1 \mathrm{~N}(t=3.62, \mathrm{p}<0.01)$ and 2 $\mathrm{N}(\mathrm{t}=5.70, \mathrm{p}<0.01)$; and for the tongue at 0.5 $\mathrm{N}(t=3.14, \mathrm{p}<0.01), 1 \mathrm{~N}(t=7.09, \mathrm{p}<0.01)$, and $2 \mathrm{~N}(t=7.83, \mathrm{p}<0.01)$. Moreover, the hold phase of the unstimulated patients was not so steady as that of the stimulated patients as indicated by the greater SD.

\section{Discussion}

Bilateral stimulation of the STN greatly improved motor control in this group of patients, who were studied without medication. The $42 \%$ to $87 \%$ improvement in the global motor evaluation of the UPDRS part 3 reflects the good sensitivity of the parkinsonian syndrome to STN stimulation. In the same way, the item dysarthria of the UPDRS was improved. However, the use of a qualitative five point scale to estimate precisely speech disorders is inadequate and electrophysiological measurements of the speech organs turned out to be necessary. We examined the production of lip and tongue force of the patients under two conditions: without and with bilateral stimulation, considering the difference between both conditions as an index of the influence of the bilateral STN stimulation. Stimulation favourably influenced the patients' articulatory organs. In stimulated patients we noted a large increase in maximal voluntary force of the lips and tongue, which approached that of the control subjects. These results agree with those of a study relative to the limbs of STN stimulated patients. ${ }^{22}$ Indeed, the maximal strength of the forearm extensors during an isometric contraction against a strain gauge was increased by a mean of $195 \%$ in the stimulated condition. This increase in force by STN stimulation might contribute to the decrease in bradykinesia and could explain the decrease in force rise time measured in the stimulated condition. For each effector organ, force rise times were different for four different levels of force which were generated by the subjects. To simplify calculations, for each articulatory organ we pooled the data for different levels. The force rise times of the controls were significantly shorter than those of the stimulated and unstimulated patients, whatever the speech organ, and the force rise times of the stimulated patients were shorter than those of the unstimulated patients for the upper and lower lips.

In addition, the undershoot of the peak force was a common feature of the unstimulated patients. The task required in this study was, at least partly, of a ballistic type; several authors $^{23}{ }^{24}$ have argued that a fast ballistic movement was slow in Parkinson's disease because the size of the initial impulsive activity in the agonist was reduced. So, the velocity of the resulting movement was too slow and the displacement achieved undershot the target. With STN stimulation, the patients slightly overshot the target or approximated to the different force target levels. This increase in precision of the peak force of the articulatory organs in the stimulated patients is compatible with a decrease in force rise time, possibly related to a greater muscular activity. In particular, the lower lip was found to be more precise in reaching the target than were the other articulatory organs. Several factors may account for contraction accuracy of the lower lip. Elevation of the lower lip results primarily from the contribution of two muscles, the orbicularis inferior and mentalis. The muscular synergy and the kinematic role of the lower lip during speech can explain differences in fine motor control mostly between both lips. ${ }^{25}$

Mean reaction times of the stimulated patients were shorter than those of the unstimulated patients. These findings confirm the antiakinetic effect of STN stimulation, previously shown in several studies. ${ }^{526}$

The hold phase of the control subjects was accurate and steady. The unstimulated patients had difficulty in maintaining a given contraction with the articulatory organs. MilnerBrown et $a l^{27}$ reported that, even when voluntarily attempting to maintain a force, some motor units in patients with Parkinson's disease stop firing for prolonged periods or fire at abnormally low frequencies. In addition we cannot exclude the possibility that the disturbance in maintaining a constant force may be due to a dysfunction of the integration of proprioceptive inputs. ${ }^{28}$ Hold phase accuracy of the stimulated patients was greater than that of the unstimulated patients.

In conclusion, bilateral STN stimulation influences both oral and limb systems. We noted an improvement in force of the articulatory organs and concomitant improvement in speech assessment. However, when using excessively high stimulation parameters or with incorrect electrode location, speech may be worsened by STN stimulation. Consequently, it may be helpful in determining whether a speech problem is related to stimulation. The mechanism of action of STN stimulation is unknown, although it is probable that it modulates neuronal structures involved in speech. Further speech investigations in a large number of patients are warranted to clarify the role of STN stimulation on parkinsonian dysarthria. A better knowledge of the impact of this surgical procedure on speech is very important given that dysarthria may greatly reduce the ability of the parkinsonian patients to function fully in society.

1 Marsden CD, Parkes JD. On-off effects on patients with Parkinson's disease on chronic levodopa therapy. Lancet 1976;i:92-6.

2 Alexander GE, Crutcher MD. Functional architecture of basal ganglia circuits: neural substrates of parallel processing. Trends Neurosci 1990;13:266-71.

3 Delong MR. Primate models of movement disorders of basal ganglia. Trends Neurosci 1990;13:281-5.

4 Pollak P, Benabid AL, Limousin P, et al. Chronic intracerebral stimulation in Parkinson's disease. In: Obeso JA, Delong MR, Ohye C, et al, eds. The basal ganglia and new surgical approaches for Parkinson's disease. Advances in Neurology 74. Philadelphia: Lippincott-Raven, 1997:59194.

5 Limousin P, Krack P, Pollak P, et al. Electrical stimulation of the subthalamic nucleus in advanced Parkinson's disease. N Engl f Med 1998;339:1105-11.

6 Limousin P, Greene J, Pollak P, et al. Changes in cerebral activity pattern due to subthalamic nucleus or internal pallidum stimulation in Parkinson's disease. Ann Neurol 1997; 42:283-91. 
7 Jenkins A. Speech following stereotaxic operations for the relief of tremor and rigidity in parkinsonism. Med 7 Aust relief of tremo
$1968 ; 7: 585-8$

8 Samra K, Riklan M, Levita E, et al. Language and speech correlates anatomically verified lesions in thalamic surgery for parkinsonism. I Speech Hear Res 1969;12:510-40

9 Nagajeki Y, Shibiazaki T, Firai T, et al. Long term follow up results of selective VIM thalamotomy. $\mathcal{F}$ Neurosurg 1986;65 296-302.

10 Stracciari A, Guarino M, Cirignotta F, et al. Development of palilalia after stereotaxic thalamotomy in Parkinson's disease. Eur Neurol 1993;33:275-76.

11 Benabid AL, Pollak P, Gao D, et al. Chronic electrical stimulation of the ventralis intermedius nucleus of the thalamus as a treatment of movement disorders. $f$ Neurosurg 1996;84:203-14.

12 Pfann KD, Penn RD, Shannon KM, et al. Effect of stimulation in the ventral intermediate nucleus of the thalamus on limb control in Parkinson's disease. A case study. Mov Disord 1996;11:311-16.

13 Stein RB. What muscle variables does the central nervous system control? Behav Brain Sci 1982;5:535-78.

14 Barlow SM, Abbs JH. Force transducers for the evaluation Barlow SM, Abbs JH. Force transducers for the evaluation
of labial, lingual, and mandibular motor impairments. $\mathcal{f}$ of labial, lingual, and mandibular

15 Dworkin JP, Aronson AE, Muller DW. Tongue force in normals and in dysarthric patients with amyotrophic latera sclerosis. F Speech Hear Res 1980;23:828-37.

16 Hunker CJ, Abbs JH, Barlow SM. The relationship between parkinsonian rigidity and hypokinesia in the orofacial system: a quantitative analysis. Neurology 1982;32:749-54.

17 Wood M, Hughes J, Hayes KC, et al. Reliability of labial closure force measurements in normal subjects and patients with CNS disorders. $\mathcal{F}$ Speech Hear Res 1992;35:252-8.

18 McHenry MA, Minton JT, Wilson RL, et al. Intelligibility and nonspeech orofacial strength and force control following traumatic brain injury. I Speech Hear Res 1994;37: ing traum $1271-83$.
19 McNeil MR, Weismer G, Adams S, et al. Oral structure nonspeech motor control in normal, dysarthric, aphasic, and apraxic speakers: isometric force and static position control. F Speech Hear Res 1990;33:255-68.

20 Luschei ES. Development of objective standards of non-speech oral strength and performance. In: Moore CA, Yorkston KM, Beukelman DR, eds. Dysarthria and apraxia of speech: perspectives on management. Baltimore: Paul $\mathrm{H}$ of speech: perspectives
Brookes, 1991:3-14.

21 Fahn S, Elton RI, and Members of the UPDRS development Committee. The unified Parkinson's disease rating scale. In: Fahn S, Marsden CD, Calnen DB, et al, eds. Recents developments in Parkinson's disease. New Jersey: MacMillan Healthcare Information, 1987:153-64.

22 Limousin P, Brown R, Brown P, et al. Effect of subthalamic (STN) stimulation on motor function in Parkinson's disease (PD) I: clinical and physiological measures, 27th annual meeting Society for Neuroscience [abstracts]. 1997;23:416.

23 Hallett M, Khosbin S. A physiological mechanism of bradykinesia. Brain 1980;115:465-80.

24 Marsden CD. Neurophysiology. In: Stern GM, ed. Parkinson's disease. London: Chapman and Hall Medical, 1990.

25 Gentil M, Tournier CL. Differences in fine control of forces generated by the tongue, lips, and fingers in humans. Arch Oral Biol 1998;43:517-23.

26 Krack P, Pollak P, Limousin P, et al. Subthalamic nucleus or internal pallidal stimulation in young onset Parkinson's disease. Brain 1998;121:451-7.

27 Milner-Brown HS, Fisher MA, Weiner J. Electrical properties of motor units in parkinsonism and a possible relation with bradykinesia. F Neurol Neurosurg Psychiatry 1979;42: 35-41.

28 Schneider JS, Shirley G, Diamond BA, et al. Deficits in orofacial sensorimotor function in Parkinson's disease. Ann Neurol 1986;19:275-82. 